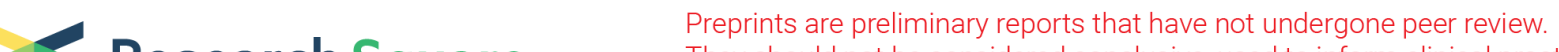 Research Square They should not be considered conclusive, used to inform clinical practice, or referenced by the media as validated information.
}

\section{Emergence of OXA-10 and OXA-48 like carbapenemases among Enterobacter isolates from inpatients in southern Iran}

\section{Melika Moradi}

Department of Bacteriology and Virology, School of Medicine, Shiraz University of Medical Sciences, Shiraz, Iran

Reza Khashei ( $\nabla$ khasheir@sums.ac.ir)

Shiraz University of Medical Sciences Medical School

\section{Yalda Malekzadegan}

Department of Bacteriology and Virology, School of Medicine, Shiraz University of Medical Sciences, Shiraz, Iran

\section{Jamal Sarvari}

Department of Bacteriology and Virology, School of Medicine, Shiraz University of Medical Sciences, Shiraz, Iran

\section{Research}

Keywords: Enterobacter, Carbapenemase, Oxacillinase, Integron, Iran

Posted Date: July 7th, 2021

DOl: https://doi.org/10.21203/rs.3.rs-673753/v1

License: (c) (i) This work is licensed under a Creative Commons Attribution 4.0 International License. Read Full License 


\section{Abstract \\ Background}

The global spread of carbapenemase-producing Enterobacteriaceae represents a public health concern. The aim of this study was to investigate prevalence of carbapenem resistance, oxacillinase types and the presence of class 1-3 integrons among Enterobacterclinical isolates from an Iranian inpatients' population.

\section{Methods}

Ninety Enterobacter isolates recovered from hospitalized patients were diagnosed by the standard microbiological methods. Antibiogram pattern was also determined. The presence of class 1-3 integrons and four types of oxacillinase genes were assessed using PCR.

\section{Results}

Of the 90 Enterobacterisolates, the most common species was identified as E. aerogenes, (45.6\%), followed by E. cloacae (30\%). The highest resistance rate was against to ampicillin (96.7\%). Multi-drug resistance (MDR) was substantial (93\%). Carbapenemase producers were detected in $96 \%$ of carbapenem resistant isolates by $\mathrm{mCIM}$ test. The frequency of evaluated genes was as follows: int $11=50$ $(55.6 \%)$, int $/ 2=12(13.3 \%), b / a_{\text {oxa-1 }}=6(6.7 \%), b / a_{\text {oxa }-2}=5(5.6 \%), b / a_{\text {oxa }-10}=18(20 \%)$, and $b / a_{\text {oxa }-48}=18$ (20\%).

\section{Conclusion}

The determinants of class 1 integron with OXA-10 and OXA-48 like carbapememases have been responsible of relatively considerable of carbapenem resistance among isolates. This is the first OXA-10 and OXA-48-producing Enterobacterspp. in Iran, indicating that the prevalence of oxacillinases might be on the rise in country.

\section{Background}

Enterobacter as an important Gram-negative rod among Enterobacteriaceae members is responsible for wide range of nosocomial infections, in particular bloodstream (BSI), respiratory tract (RTI) and urinary tract infections (UTI) [1, 2]. The emergence of nosocomial infections due to Enterobacter spp. are associated with a remarkable of morbidity and mortality, especially among hospitalized patients at intensive care units (ICUs) $[3,4]$. 
Betalactams, especially thirdgeneration cephalosporins and carbapenems are frequently used to treat infections caused by Enterobacter spp.[5, 6]. However, Enterobacter cloacae and Enterobacter aerogenes as the most frequently isolated species are intrinsically resistant to many drugs [7]. Moreover, acquisition of multi-drug resistance (MDR) among Enterobacter spp. is increasing, so that has severely been compromised the available therapies [8]. Nosocomial infections caused by carbapenem-resistant Enterobacteriaceae (CRE) are considered a challenge to patients, physicians, and public health, and this subject is due to capability of their widespread across the world. A mortality rate of $30-44 \%$ has been attributed to infections caused by CRE $[9,10]$. The main mechanism of carbapenem resistance in Enterobacteriaceae, including Enterobacterspp. is carbapenemase production. According to the Ambler classification, molecular class D or OXA-type carbapenemases as plasmid-encoded $\beta$-lactamases, more recently, have transmitted into the Enterobacteriaceae and are becoming a considerable cause of carbapenem resistance $[9,11]$. They are active on extended-spectrum cephalosporins, monobactams (ESBL), and the carbapenems [12]. There are different types of carbapenem hydrolyzing OXA-type carbapenemases, including OXA-48 and its variants that are widespread amongst Enterobacteriaceae members and accounted one of the most concerning developments in CRE isolates in the last decade [11]. It is suggested that among different carbapenemases, OXA-48 is the most predominant in Mediterranean and Middle East countries [13]. Furthermore, integrons as one of the mobile genetic elements have a major role in wide spread of antibiotic resistance among bacteria. To date, four general classes of integrons, namely classes 1-4 have been introduced, in which classes 1-3 integrons are capable of acquiring gene cassettes through site-specific recombination and regarded as the frequent classes involved in therapeutic failure among Gram-negative rods[14, 15]. There are few reports of carbapenemase-producing Enterobacterspp. from Iran. The present study aimed to investigate some OXA-type carbapenemase genes and the presence of class 1-3 integrons among clinical isolates of Enterobacterfrom inpatients in southern Iran.

\section{Methods}

\section{Clinical isolates}

The study was carried out between August 2018 and April 2019 using 90 non-duplicated Enterobacter isolates obtained from hospitalized patients at Shiraz Namazi Teaching Hospital, southern Iran. Only one isolate was collected from per patient. Of these 90 isolates, 40 were belonged to a previous study [16]. The isolates were recovered from different clinical samples, including blood, wound, endotracheal tube aspirates, abdominal discharge, urine, and eye. Primary identification of Enterobacter isolates was performed by standard microbiological tests and confirmed in species level by Microgene ${ }^{\text {TM }} \mathrm{GnA}+\mathrm{B}-\mathrm{ID}$ system (Microgen Bioproducts Ltd, UK) diagnostic kit (Mast, UK) according to the manufacturer instructions. All the confirmed isolates were stored in tryptic soy broth (TSB) (Merck Co., Germany) containing $20 \%$ glycerol at $-70{ }^{\circ} \mathrm{C}$ until further use. This study was following the declaration of Helsinki and approved by the Ethics Committee of Shiraz University of Medical Sciences (approval number IR.SUMS.REC.1397.816). 
Antibiotic susceptibility of all isolates to amikacin, ampicillin, amoxicillin/clavulanate, imipenem, ciprofloxacin, nitrofurantoin, trimethoprim-sulfamethoxazole (SXT), ceftazidime, cefoxitin and gentamicin (Mast Co., UK) was performed on Muller-Hinton agar plates (Merck Co., Germany) using the disk diffusion method according to Clinical and Laboratory Standards Institute (CLSI) guidelines [17]. E. coli ATCC 25922 was used as the quality control strain. MDR was defined as non-susceptibility to $\geq 1$ agent in $\geq 3$ different antibiotic classes [18].

\section{Carbapenemase phenotypic detection}

Detection of carbapenemase-producing Enterobacterspp. was performed and interpreted by the modified carbapenem inactivation method ( $\mathrm{mCIM})$ in accordance with CLSI recommendations [17]. Briefly, suspension of bacteria was suspended in $2 \mathrm{~mL}$ of TSB, and a $10 \mu \mathrm{g}$ meropenem disk (Mast Co., UK) was added prior to incubation at $35^{\circ} \mathrm{C}$ for $4 \mathrm{~h}$. Meropenem disk was then transferred onto on Muller-Hinton agar, inoculated with a $0.5 \mathrm{McF}$ arland suspension of Escherichia coli ATCC 25922, and incubated at $35^{\circ} \mathrm{C}$ for 18 to $24 \mathrm{~h}$. The presence of carbapenemase activity was recognized by an inhibition zone $\leq 15 \mathrm{~mm}$ in diameter or presence of pinpoint colonies within a 16-18 mm zone, and absence of carbapenemase activity was revealed by zones $\geq 19 \mathrm{~mm}$ (clear zone) in diameter [19].

Class 1, 2 and 3 integrons and oxacillinase resistance genes assay

Genomic DNA of Enterobacterspp. was extracted by the simple boiling method as previously described [20]. The presence of potential resistance genes encoding class 1, 2 and 3 integrons and oxacillinase, including int/1, int $/ 2$, int $/ 3$ integrases and $b / a_{\text {oxa- } 1}, b / a_{\text {oxa-2 }}, b / a_{\text {oxa }-10}$ and $b / a_{\text {oxa-48 }}$ were screened by PCR amplification using specific previously reported primers [21-25]. PCR reactions were carried out using a thermal cycler 5530 (Ependrof master, Germany) with $2 \mu \mathrm{L}$ of each specific primer $(1 \mu \mathrm{M}), 1 \mu \mathrm{L}$ DNA template (100 ng), and 12.5 $\mu \mathrm{L}$ Premix PCR buffer (Amplicon, Denmark) (1X), in a total volume of $25 \mu \mathrm{L}$. PCRs consisted of initial denaturation at $94^{\circ} \mathrm{C}$ for $5 \mathrm{~min}$, followed by 35 cycles of denaturation at $94^{\circ} \mathrm{C}$ for $45 \mathrm{sec}$, primer annealing at $55^{\circ} \mathrm{C}$ for int $/ 1$ and $58^{\circ} \mathrm{C}$ for int $/ 2$ and int $/ 3$ and extension step at $72^{\circ} \mathrm{C}$ for 60 $\mathrm{sec}$, and a final extension at $72^{\circ} \mathrm{C}$ for $7 \mathrm{~min}$. For the $b / a_{\text {oxa- }-1}, b / a_{\text {oxa }-2}, b / a_{\text {oxa }-10}$ and $b / a_{\text {oxa-48 }}$ genes, annealing temperature were chosen at $48,59,54$, and $60^{\circ} \mathrm{C}$, respectively. PCR products were electrophoresed on $1.5 \%$ agarose gel, stained with KBC power load dye (CinnaGen Co. Iran) and visualized in gel documentation system. The amplicons of blaxa-48-like gene-producing isolates were submitted for sequencing (Bioneer Co., Munpyeongseoro, Daedeok-gu, Daejeon, South Korea) and results were analyzed using the GenBank database of the National Center for Biotechnology Information through BLAST network service (http://www.ncbi.nlm.nih.gov/BLAST/).

\section{Statistical analysis}

The analysis was done using SPSS ${ }^{\text {TM }}$ software, version 21.0 (IBM Corp., USA). Chi-square or Fisher's exact tests were used and differences were considered statistically significant when the p-value was less than 
0.05 .

\section{Results}

Study population and clinical characteristics of Enterobacter isolates

Our isolates were recovered from 90 individuals admitted as inpatients, consisting of $25(27.8 \%)$ female and $65(72.2 \%)$ males with a median age of 33 years (range = 8 days to 76 years). Among Enterobacter isolates, 58 (64.4\%) isolates were obtained from the intensive care units (ICUs), 24 (26.7\%) from the internal units and $8(8.9 \%)$ from the surgery units. The isolates were obtained from RTI $(n=34,37.8 \%)$, UTI $(n=20,22.2 \%), B S I(n=16,17.8 \%)$, skin and soft tissue infection (SSTI) $(n=14,15.6 \%)$ and other sources $(n=6,6.6 \%)$. All 90 clinical isolates of Enterobacterwere classified as E. aerogenes $(n=41$, $45.5 \%)$, E. cloacae $(n=27,30 \%)$, E. gergoviae $(n=14,15.6 \%)$ and Cronobacter $(E)$ sakazakii $(n=8,8.9 \%)$.

\subsection{Antimicrobial resistance of Enterobacterspp.}

Results of susceptibility testing are represented in Table 1. All isolates showed resistance to all antimicrobials with different proportions. According to these results, the highest resistance rate (nonsusceptible isolates) was against to ampicillin (96.7\%), whereas the lowest resistance was toward amikacin (24.4\%). Amongst different species, C. sakazakii isolates revealed the highest $(68.7 \%)$ resistance to antimicrobial agents, followed by E. aerogenes (64.6\%). The majority of isolates $(n=84$, 93\%) exhibited a multi-drug resistant (MDR) phenotype. Out of 90 Enterobacter spp., 25 (27.8\%) were phenotypically non-susceptible to carbapenem (imipenem as representative of carbapenems, Table 1). Among 25 carbapenem-resistant isolates, 24 (96\%) showed positive results in mCIM test. All the mCIM positive isolates were MDR. 
Table 1

Antibiotic resistance pattern of Enterobacter spp.

\begin{tabular}{|c|c|c|c|c|c|}
\hline Antibiotic & $\begin{array}{l}E . \\
\text { aerogenes } \\
\text { (total = 41) }\end{array}$ & $\begin{array}{l}\text { E. cloacae } \\
)^{\text {(total }=27}\end{array}$ & $\begin{array}{l}\text { E. } \\
\text { gergoviae } \\
\text { (total = } 14\end{array}$ & $\begin{array}{l}\text { C. } \\
\text { sakazakii } \\
(\text { total = 8) }\end{array}$ & $\begin{array}{l}\text { Total } \\
\text { (No., \%) }\end{array}$ \\
\hline Ampicillin & $39(95.1)$ & $26(96.3)$ & $14(100)$ & $8(100)$ & $\begin{array}{l}87 \\
(96.7)\end{array}$ \\
\hline Amoxicillin-clavulanate & $39(95.1)$ & 24(88.9) & 13(92.9) & $8(100)$ & $\begin{array}{l}74 \\
(82.2)\end{array}$ \\
\hline Cefoxitin & $34(82.9)$ & 25(92.6) & $11(78.6)$ & $8(100)$ & $\begin{array}{l}78 \\
(86.7)\end{array}$ \\
\hline Ceftazidime & $34(82.9)$ & $20(74.1)$ & $11(78.6)$ & $8(100)$ & $\begin{array}{l}73 \\
(81.1)\end{array}$ \\
\hline Ciprofloxacin & 16(39) & $9(33.3)$ & $4(28.6)$ & $3(37.5)$ & $\begin{array}{l}32 \\
(35.5)\end{array}$ \\
\hline Amikacin & 13(31.7) & $3(11.1)$ & $2(14.3)$ & $4(50)$ & $\begin{array}{l}22 \\
(24.4)\end{array}$ \\
\hline Gentamicin & 19(46.3) & $10(37)$ & $6(42.9)$ & $3(37.5)$ & $\begin{array}{l}38 \\
(42.2)\end{array}$ \\
\hline Trimethoprim/sulfamethoxazole & $23(56.1)$ & $10(37)$ & $9(64.3)$ & $4(50)$ & $\begin{array}{l}46 \\
(51.1)\end{array}$ \\
\hline Nitrofurantoin & $34(82.9)$ & 23(85.2) & $9(64.3)$ & $6(75)$ & $72(80)$ \\
\hline Imipenem & $14(34.1)$ & $6(22.2)$ & $2(14.3)$ & $3(37.5)$ & $\begin{array}{l}25 \\
(27.8)\end{array}$ \\
\hline
\end{tabular}

Characterization of integrase and oxacillinase genes

PCR analysis of the three classes of integron genes showed that $50(55.6 \%)$ and $12(13.3 \%)$ isolates were carried int/ 1 and int/2 genes, respectively. Class 3 integron (int/3) was not found in any of the isolates. The antimicrobial resistance patterns of classes 1 and 2 integron-positive and negative isolates are presented in Tables 2 and 3, correspondingly. A statistically significant difference was determined between the presence of class 2 integron and higher rate of antimicrobial resistance related to ceftazidime and trimethoprim-sulfamethoxazole (Table 3). 
Table 2

Antibiotic susceptibility pattern of Enterobacterisolates according to the presence of class 1 integron

\begin{tabular}{|llll|}
\hline Antibiotic & Integron-1 positive & Integron-1 negative & p-value \\
& $\mathbf{n}=\mathbf{5 0}$ & $\mathbf{n}=\mathbf{4 0}$ & \\
\hline No. (\%) & No. (\%) & \\
\hline Ampicillin & $49(98)$ & $38(95)$ & 0.5 \\
\hline Amoxicillin-clavulanate & $46(92)$ & $38(95)$ & 0.6 \\
\hline Cefoxitin & $42(84)$ & $36(90)$ & 0.5 \\
\hline Ceftazidime & $43(86)$ & $30(75)$ & 0.2 \\
\hline Ciprofloxacin & $16(32)$ & $16(40)$ & 0.5 \\
\hline Amikacin & $10(20)$ & $12(30)$ & 0.3 \\
\hline Gentamicin & $20(40)$ & $18(45)$ & 0.6 \\
\hline Trimethoprim/sulfamethoxazole & $22(44)$ & $16(40)$ & 0.1 \\
\hline Nitrofurantoin & $38(76)$ & $34(85)$ & 0.4 \\
\hline Imipenem & $12(24)$ & $13(32.5)$ & 0.4 \\
\hline
\end{tabular}


Table 3

Antibiotic susceptibility pattern of Enterobacterisolates according to the presence of class 2 integron

\begin{tabular}{|llll|}
\hline Antibiotic & $\begin{array}{l}\text { Integron-2 positive } \\
\mathbf{n}=12\end{array}$ & $\begin{array}{l}\text { Integron-2 negative } \\
\mathbf{n}=\mathbf{7 8}\end{array}$ & $p$-value \\
& No. (\%) & No. (\%) & \\
\hline Ampicillin & $12(100)$ & $75(96.2)$ & 1.00 \\
\hline Amoxicillin-clavulanate & $10(83.3)$ & $74(94.9)$ & 0.1 \\
\hline Cefoxitin & $8(66.7)$ & $70(89.7)$ & 0.05 \\
\hline Ceftazidime & $7(58.3)$ & $66(84.6)$ & 0.04 \\
\hline Ciprofloxacin & $1(8.3)$ & $31(39.7)$ & 0.05 \\
\hline Amikacin & $2(16.7)$ & $20(25.6)$ & 0.7 \\
\hline Gentamicin & $4(33.3)$ & $34(43.6)$ & 0.5 \\
\hline Trimethoprim/sulfamethoxazole & $2(16.7)$ & $44(56.4)$ & 0.01 \\
\hline Nitrofurantoin & $11(91.7)$ & $61(78.2)$ & 0.4 \\
\hline Imipenem & $2(16.7)$ & $23(29.5)$ & 0.5 \\
\hline
\end{tabular}

Moreover, 18 (20\%) isolates were harbored both $b l a_{\text {oxa-10 }}$ and $b l a_{\text {oxa-48 }}$-like genes with different distributions among Enterobacter spp., and 6 (6.7\%) and 5 (5.6\%) ones were positive for the $b / a_{\text {oxa- }}$, and $b / a_{\text {oxa-2 }}$ genes, respectively (Table 4). On the other hand, only $4(16.6 \%) \mathrm{mCIM}$ positive isolates were carried $b / a_{\text {oxa-48 }}$-like gene and other oxacillinase genes were not detected among these isolates. $\mathrm{A}$ statistically significant difference was diagnosed between the presence of $b / a_{\text {oxa-10 }}$ and $b / a_{\text {oxa-2 }}$ genes with higher rate of antimicrobial resistance related to ceftazidime (data not shown). Meanwhile, sequencing results confirmed that $b / a_{\text {oxa- } 48}$-like positive isolates were $b / a_{0 \times a-48}$ variant. 
Table 4

Distribution of studied genes according to Enterobacter spp.

\begin{tabular}{|lllll|}
\hline Gene & $\begin{array}{l}\text { E. aerogenes } \\
(\mathbf{n}=\mathbf{4 1})\end{array}$ & $\begin{array}{l}\text { E. cloacae } \\
(\mathbf{n}=\mathbf{2 7})\end{array}$ & $\begin{array}{l}\text { E. gergoviae } \\
(\mathbf{n}=14)\end{array}$ & $\begin{array}{l}\text { C. sakazakii } \\
(\mathbf{n}=\mathbf{8})\end{array}$ \\
\hline Int1 & $17(41.5)$ & $17(63)$ & $9(64.3)$ & $7(87.5)$ \\
\hline Int2 & $5(12.2)$ & $3(11.1)$ & $4(28.6)$ & - \\
\hline oxa-1 & $2(4.9)$ & $2(7.4)$ & - & $2(25)$ \\
\hline oxa-2 & - & $3(11.1)$ & $2(14.3)$ & - \\
\hline oxa-10 & $9(22)$ & $5(18.5)$ & $2(14.3)$ & $2(25)$ \\
\hline oxa-48 & $7(17.1)$ & $7(25.9)$ & $3(21.4)$ & $1(12.5)$ \\
\hline
\end{tabular}

The frequency of int $/ 1$, int $/ 2$ and $b / a_{\text {oxa-1 }}, b / a_{\text {oxa-2 }}, b / a_{\text {oxa-10 }}$ and $b / a_{\text {oxa-48 }}$ genes were more prevalent among C. sakazakii, E. gergoviae, C. sakazakii, E. gergoviae, C. sakazakii, and E. cloacae, respectively.

\section{Discussion}

An increase in the emergence of $\mathrm{CRE}$, including Enterobacter spp. leaving limited treatment options, therefore are related to high morbidity and mortality $[3,4,8]$. In the current study, we determined antimicrobial resistance pattern and the presence of integrase and oxacillinase genes among 90 Enterobacter clinical isolates obtained from a tertiary care hospital from south of Iran. According literature, E. cloacae and E. aerogenes are the most prevalent clinical isolates of Enterobacter [8]. In consistent with literature, in our survey $E$. aerogenes and $E$. cloacae were also the most common species with frequencies 45.6 and $30 \%$, respectively. On the contrary, in the study of Khashei et al., E. gergoviae (54.2\%) was found the most frequently isolated species [16]. Enterobacterisolates have been the leading cause of nosocomial infections all over the world [1, 2]. In our work, most of isolates $(37.8 \%)$ were recovered from respiratory tract samples. In agreement with our survey, in two study from China and Germany 91 and $37.8 \%$ of isolates were obtained from RTIs, respectively [10, 26]. In contrast, in several investigations blood and abdominal samples were the most frequent sites of Enterobacterisolation [8, $27,28]$. In this study, $64.4 \%$ of isolates were recovered from ICU ward. Likewise, some studies nationwide shared similar findings $[26,29]$. This issue indicates the importance of long-term hospitalization for acquisition of these infections.

In susceptibility testing, all isolates were resistant to all of the tested antimicrobials, with $93 \%$ of strains showing MDR phenotype, making them a major therapeutic treat in our area. Based on CLSI, resistance to one or more carbapenems is considered as carbapenem resistance [27]. Hence, $27.8 \%$ our isolates were non-susceptible to imipenem (carbapenem resistant). The result is coinciding with two previously reported works from Iran and China with prevalence's of 29.2 and $25.7 \%$, respectively [16,30]. Moreover, among carbapenem-resistant isolates, $96 \%$ were phenotypically carbapenemase producers by $\mathrm{mCIM}$ test. 
The $\mathrm{mCIM}$ is a reliable and simple method and has a sensitivity of $98-100 \%$ in comparison with the modified Hodge test and the carbapenemase Nordmann-Poirel (carba NP) test with sensitivities of 93$98 \%$ and $73-100 \%$, respectively. Furthermore, due to being expensive of PCR, mCIM could be a suitable alternative method for detecting of carbapenemase producers [12, 31-33].

In addition to rapid phenotypic tests, genotypic identification of carbapenemases among Gram-negative rods is an important step for infection control and prevention. The major mechanism of resistance to carbapenems among Enterobacter isolates is carbapenemase production, mainly OXA-type carbapenemases, including $b / a_{\text {oxa-1 }}, b / a_{\text {oxa-2 }}, b / a_{\text {oxa }-10}$ and $b / a_{\text {oxa-48 }}$-like genes and metallobetalactamases with a less prevalence [22]. In the current work, the presence of $b / a_{\text {oxa- }}, b / a_{\text {oxa-2 }}$, $b / a_{\text {oxa }-10}$ and $b / a_{\text {oxa-48 }}$-like genes were diagnosed with frequencies $6.7,5.6,20$, and $20 \%$, respectively. The presence of oxacillinase genes in Enterobacter spp. are less than other Enterobacteriaceae members and their prevalence varies across the world. The $b / a_{\text {oxa }-48}$ first time identified among Klebsiella pneumoniae isolates in 2004 from Turkey. Afterward, the gene reported in some other Enterobacterales, including E. cloacae in Middle East, Africa and Europe [34, 35]. But this gene along with other oxacillinase

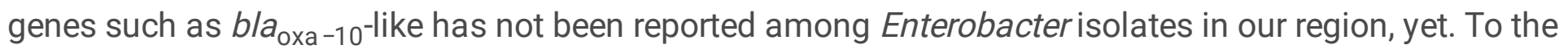
best of our knowledge, this will be the first reporting on Enterobacterspp. harboring $b / a_{0 x a-10}$ and $b / a_{\text {oxa }}-48^{-l i k e}$ genes from Iran.

In three studies conducted in Russia, Turkey and Germany, the prevalence of $b / a_{\text {oxa-48 }}$ among Enterobacterisolates was reported as $20,34.8$ and $10.7 \%$, respectively [36-38]. In addition, our results revealed that $6.7 \%$ and $5.6 \%$ of isolates were positive for $b / a_{\text {oxa- }-1}$ and $b / a_{\text {oxa- }}$-like genes, correspondingly. The result was less slightly than those observed by Ramezanzadeh and colleague with prevalence's of $7.7 \%\left(b / a_{\text {oxa-1 }}\right)$ and $11.8 \%$ (b/a oxa-2) [39]. In this survey, we found only $16.6 \%$ of $\mathrm{mCIM}$ positive isolates were carried $b / a_{\text {oxa-48 }}$-like gene, indicating other mechanisms such as metallobetalactamases or $\mathrm{OmpK}$ gene that regulates expression of mutated efflux pump are involved in carbapenem resistance. These discrepancies on phenotypic and genotypic results are also cited by some authors $[13,33,40-42]$.

On the other hand, we identified the presence of class 1, 2 and 3 integrons among our isolates. Carbapenemase genes are harbored on mobile genetic elements and can be disseminated to other bacteria, therefore contributing to the origin of antimicrobial resistance among Enterobacteriaceae members [32]. It is reported that class 1 integron is found in $40-70 \%$ of Gram-negative pathogens and has had a major role in widespread of antibiotic resistance $[14,15]$. In consistent with literature, int/1 was found in the highest rate $(55.6 \%)$, followed by int/2 (13.3\%) and $8.9 \%$ of isolates were positive for both classes of integron genes, simultaneously. However, a significant difference was determined between isolates harboring int/2 gene and higher rate of drug resistance with only two antibiotics (Table 3 ). In accordance to our results, Mortazavi et al. showed that $58.3 \%$ of E. cloacae isolates, harbored class I integron; however, none of them had class II integron [43]. In the present work, the int/3 gene was not detected in any of the isolates. It is mentioned that distribution of class 3 integron has been limited within 
a few Gram-negative bacteria, with the exception of Enterobacter spp. ranged from $0-10 \%$, which is according to our findings [15].

This investigation had several limitations. First, the sample size was relatively small. Second, due to lack of temocillin disk $(30 \mu \mathrm{g})$ we could not phenotypically diagnose OXA-48-producing isolates. Third, we could not evaluate the presence of more OXA-type carbapenemase genes to better assess of oxacillinase resistance among our isolates.

\section{Conclusion}

In the current study, OXA-10 and OXA-48-type carbapenemases were detected in $20 \%$ of carbapenem resistant Enterobacter isolates, indicating that these oxacillinase genes are probably the most common mode of resistance to carbapenems in our geographical region. Dissemination of antibiotic resistant isolates co-producing an oxacillinase and integrases increases clinical concern and may become an important therapeutic challenge in the future. Finally, identification and prevalence of different classes of integron among Gram-negative rods involved in nosocomial infections, as well as different types of oxacillinase genes require further investigation.

\section{Declarations}

\section{Acknowledgments}

The authors wish to thank all staff in Microbiology laboratory of Namazi hospital for providing of culture media. Their support and collaboration are gratefully acknowledged. This work is extracted from M.Sc thesis of Melika Moradi in partial fulfillment of the requirements for the Medical Microbiology Master's degree.

\section{Authors' contributions}

RK designed the study, MM and YM conducted the experiments, MM and YM analyzed the data, RK and MM wrote the manuscript which was corrected by RK, RK and JS were supervisors of the study. All authors read and approved the final manuscript.

Funding: This work was supported by Shiraz University of Medical Sciences, (Grant number 97-01-0117115).

\section{Availability of data and materials}

The datasets used and/or analyzed during the current study are available from the corresponding author on reasonable request.

\section{Ethics approval and consent to participate}


This study was in accordance with the declaration of Helsinki and an ethical permission was sought from the institutional Ethics Committee of Shiraz University of Medical Sciences (Approval No. IR.SUMS.REC. 1397.816). As we only used leftovers from clinical specimens, the institutional ethics committee waived the need for informed consent.

\section{Consent for publication}

Not applicable.

\section{Competing interests}

The authors declare that they have no competing interests.

\section{Author details}

${ }^{1}$ Department of Bacteriology and Virology, School of Medicine, Shiraz University of Medical Sciences, Shiraz, Iran.

\section{References}

1. Davin-Regli A, Pages JM. Enterobacter aerogenes and Enterobacter cloacae, versatile bacterial pathogens confronting antibiotic treatment. Front Microbiol. 2015, 6, 392.

2. Demir T, Baran G, Buyukguclu T, Sezgin FM, Kaymaz H. Pneumonia due to Enterobacter cancerogenus infection. Folia Microbiol (Praha). 2014;59:527-30.

3. Mezzatesta ML, Gona F, Stefani S. Enterobacter cloacae complex: clinical impact and emerging antibiotic resistance. Future Microbiol. 2012;7:887-902.

4. Sligl W, Taylor G, Brindley PG. Five years of nosocomial Gram-negative bacteremia in a general intensive care unit: epidemiology, antimicrobial susceptibility patterns, and outcomes. Int $\mathrm{J}$ Infect Dis. 2006;10:320-5.

5. Khajuria A, Praharaj AK, Kumar M, Grover N. Carbapenem Resistance among Enterobacter species in a tertiary care hospital in central India. Chemother Res Pract. 2014, 2014, 972646.

6. Moxon CA, Paulus S. Beta-lactamases in Enterobacteriaceae infections in children. J Infect. 2016;72(Suppl):41-9.

7. Girlich D, Poirel L, Nordmann P. Clonal distribution of multidrug-resistant Enterobacter cloacae.. Diagn Microbiol Infect Dis. 2015;81:264-8.

8. Lee JY, Hong YK, Lee H, Ko KS. High prevalence of non-clonal imipenem-nonsusceptible Enterobacter spp. isolates in Korea and their association with porin down- regulation. Diagn Microbiol Infect Dis. 2017;87:53-9.

9. Evans BA, Amyes SG. OXA ß-lactamases. Clin Microbiol Rev. 2014;27:241-63. 
10. Bocanegra-lbarias P, Garza-González E, Morfín-Otero R, Barrios H, Villarreal-Treviño L, RodríguezNoriega E, et al. Molecular and microbiological report of a hospital outbreak of NDM-1-carrying Enterobacteriaceae in Mexico. PLoS One. 2017;12:e0179651.

11. Qin X, Yang Y, Hu F, Zhu D. Hospital clonal dissemination of Enterobacter aerogenes producing carbapenemase KPC-2 in a Chinese teaching hospital. J Med Microbiol. 2014;63:222-8.

12. Lutgring JD, Limbago BM. The problem of carbapenemase-producing-carbapenem-resistantEnterobacteriaceae detection. J Clin Microbiol. 2016;54:529-34.

13. Al-Hasan MN, Gould AP, Drennan C, Hill O, Justo JA, Kohn J, et al. Empirical fluoroquinolones versus broad-spectrum beta-lactams for gram-negative bloodstream infections in the absence of antimicrobial resistance risk factors. J Glob Antimicrob Resist. 2020;22:87-93.

14. Gillings $M$, Boucher $Y$, Labbate $M$, Holmes A, Krishnan S, Holley M, et al. The evolution of class 1 integrons and the rise of antibiotic resistance. J Bacteriol. 2008;190:5095-100.

15. Deng Y, Bao X, Ji L, Chen L, Liu J, Miao J, et al. Resistance integrons: class 1, 2 and 3 integrons. Ann Clin Microbiol Antimicrob. 2015;14:45.

16. Khashei R, Sarvestani FE, Malekzadegan Y, Motamedifar M. The first report of Enterobacter gergoviae carrying blaNDM-1 in Iran. Iran J Basic Med Sci. 2020;23:1184-90.

17. CLSI. Performance Standards for Antimicrobial Susceptibility Testing; 28th Informational Supplement. CLSI document M100-S27. Wayne: Clinical and Laboratory Standards Institute; 2018.

18. Magiorakos AP, Srinivasan A, Carey RB, Carmeli Y, Falagas ME. Giske CG, et al. Multidrug-resistant, extensively drug-resistant and pandrug-resistant bacteria: an international expert proposal for interim standard definitions for acquired resistance. Clin Microbiol Infect. 2012;18:268-81.

19. Laolerd W, Akeda Y, Preeyanon L, Ratthawongjirakul P, Santanirand P. Carbapenemase-producing carbapenem-resistant Enterobacteriaceae from Bangkok, Thailand, and their detection by the Carba NP and modified carbapenem inactivation method tests. Microb Drug Resist. 2018;24:1006-011.

20. Gajamer VR, Bhattacharjee A, Paul D, Ingti B, Sarkar A, Kapil J, et al. High prevalence of carbapenemase, AmpC $\beta$-lactamase and aminoglycosideresistance genes in extended-spectrum $\beta$ lactamase-positive uropathogens from Northern India. J Glob Antimicrob Resist. 2020;20:197-203.

21. Machado E, Cantón R, Baquero F, Galán J-C, Rollán A, Peixe L, et al. Integron content of extendedspectrum- $\beta$-lactamase-producing Escherichia coli strains over 12 years in a single hospital in Madrid, Spain. Antimicrob Agents Chemother. 2005;49:1823-9.

22. Sugumar M, Kumar KM, Manoharan A, Anbarasu A, Ramaiah S. Detection of OXA-1 $\beta$-lactamase gene of Klebsiella pneumoniae from blood stream infections (BSI) by conventional PCR and in-silico analysis to understand the mechanism of OXA mediated resistance. PLoS One. 2014;9:e91800.

23. Kiratisin P, Apisarnthanarak A, Laesripa C, Saifon P. Molecular characterization and epidemiology of extended-spectrum- $\beta$-lactamase-producing Escherichia coli and Klebsiella pneumoniae isolates causing health care-associated infection in Thailand, where the CTX-M family is endemic. Antimicrob Agents Chemother. 2008;52:2818-24. 
24. Pakbaten Toupkanlou S, Najar Peerayeh S, Pirhajati Mahabadi R. Class. A and D extended-spectrum $\beta$-Lactamases in imipenem resistant Pseudomonas aeruginosa isolated from burn patients in Iran. Jundishapur J Microbiol. 2015;8:e18352.

25. Hatrongjit R, Kerdsin A, Akeda Y, Hamada S. Detection of plasmid-mediated colistin-resistant and carbapenem-resistant genes by multiplex PCR. Methods X. 2018;5:532-6.

26. Hoffmann H, Stürenburg E. Heesemann J, Roggenkamp A. Prevalence of extended-spectrum $\beta$ lactamases in isolates of the Enterobacter cloacae complex from German hospitals. Clin Microbiol Infect. 2006;12:322-30.

27. Rosa JF, Rizek C, Marchi AP, Guimaraes T, Miranda L, Carrilho C, et al. Clonality, outer-membrane proteins profile and efflux pump in KPC-producing Enterobacter sp. in Brazil. BMC Microbiol. 2017;17:69.

28. Wang Su, Xiao SZ, Gu FF, Tang J, Guo XK, Ni YX, et al. Antimicrobial susceptibility and molecular epidemiology of clinical Enterobacter cloacae bloodstream isolates in Shanghai, China. PLoS One. 2017;12:e0189713.

29. Fernández J, Montero I, Martínez Ó, Fleites A, Poirel L, Nordmann P, et al. Dissemination of multiresistant Enterobacter cloacae isolates producing OXA-48 and CTX-M-15 in a Spanish hospital. Int J Antimicrob Agents. 2015;46:469-74.

30. Dai W, Sun S, Yang P, Huang S, Zhang X, Zhang L. Characterization of carbapenemases, extended spectrum beta-lactamases and molecular epidemiology of carbapenem-non-susceptible Enterobacter cloacae in a Chinese hospital in Chongqing. Infect Genet Evol. 2013;14:1-7.

31. Zhong H, Wu ML, Feng WJ, Huang SF, Yang P. Accuracy and applicability of different phenotypic methods for carbapenemase detection in Enterobacteriaceae: A systematic review and metaanalysis. J Glob Antimicrob Resist. 2020;21:138-47.

32. Pancotto LR, Nodari CS, Rozales FP, Soldi T, Siqueira CG, Freitas AL, et al. Performance of rapid tests for carbapenemase detection among Brazilian Enterobacteriaceae isolates. Brazilian J Microbiol. 2018;49:914-8.

33. Davoudi-Monfared $\mathrm{E}$, Khalili $\mathrm{H}$. The threat of carbapenem-resistant gram-negative bacteria in a Middle East region. Infect Drug Res. 2018;11:1831-80.

34. Lutgring JD, Zhu W, Man TJ, Avillan JJ, Anderson KF, Lonsway DR, et al. Phenotypic and genotypic characterization of Enterobacteriaceae producing oxacillinase-48-like carbapenemases, United States. Emerg Infect Dis. 2018;24:700-9.

35. Majewski P, Wieczorek P, Sacha PT, Frank M, Juszczyk G, Ojdana D, et al. Emergence of OXA-48 carbapenemase-producing Enterobacter cloacae ST89 infection in Poland. Int J Infect Dis. 2014;25:107-9.

36. Fursova NK, Astashkin El, Knyazeva Al, Kartsev NN, Leonova ES, Ershova ON, et al. The spread of bla OXA-48 and bla OXA-244 carbapenemase genes among Klebsiella pneumoniae, Proteus mirabilis and Enterobacterspp. isolated in Moscow, Russia. Ann Clin Microbiol Antimicrob. 2015;14:1-9. 
37. Baran I, Aksu N. Phenotypic and genotypic characteristics of carbapenem-resistant Enterobacteriaceae in a tertiary-level reference hospital in Turkey. Ann Clin Microbiol Antimicrob. 2016;15:20.

38. GreissI C, Saleh A, Hamprecht A. Rapid detection of OXA-48-like, KPC, NDM, and VIM carbapenemases in Enterobacterales by a new multiplex immunochromatographic test. Eur $\mathrm{J}$ Clin Microbiol Infect Dis. 2019;38:331-5.

39. Ramazanzadeh R, Rouhi S, Hosainzadegan H, Shakib P, Nouri B. Co-occurrence of extendedspectrum beta-lactamases in isolated Enterobacterspp. from patients specimens. Arch Clin Infect Dis. 2016;11:e26837.

40. Solgi H, Badmasti F, Aminzadeh Z, Giske CG, Pourahmad M, Vaziri F, et al. Molecular characterization of intestinal carriage of carbapenem-resistant Enterobacteriaceae among inpatients at two Iranian university hospitals: first report of co-production of bla $\mathrm{NDM}_{-7}$ and bla OXA-48. Eur J Clin Microbiol Infect Dis. 2017;36:2127-35.

41. Azimi L, Nordmann P, Lari AR, Bonnin RA. First report of OXA-48-producing Klebsiella pneumoniae strains in Iran. GMS Hyg Infect Control. 2014;7:9.

42. Hashemi A, Fallah F, Erfanimanesh S, Hamedani P, Alimehr S, Goudarzi H. Detection of $\beta$-lactamases and outer membrane porins among Klebsiella pneumoniae strains isolated in Iran. Scientifica. 2014;726179:6.

43. Mortazavi SH, Mansouri F, Azizi M, Alvandi A, Karbasfrushan A, Madadi-Goli N, et al. Prevalence of class I and II integrons among MDR Enterobacter cloacae isolates obtained from clinical samples of children in Kermanshah, Iran. J Clin Diagn Res. 2018;12:DC13-6.

\section{Supplementary Files}

This is a list of supplementary files associated with this preprint. Click to download.

- Additionalfile1.docx 